\title{
An Assessment of High Delivery Load Facilities under the Dakshata Program
}

Kapil Parasher ${ }^{1}$, Sanjiv Kumar ${ }^{1}$, Surendra Gupta ${ }^{1}$, Lavkush Rathore ${ }^{1}$ and Satya Prakash Mehra ${ }^{2 *}$

${ }^{1}$ Vidhan Sabha Marg, Lucknow, Uttar Pradesh, India

${ }^{2}$ Rajputana Society of Natural History, Rajputana's Shakuntalam, Village Ramnagar, PO Malah, Bharatpur, Rajasthan, India

\begin{abstract}
Goal 3 of the Sustainable Development Goals which use to be United Nations Millenium Development Goals (Goals 4 and 5) had focused on child survival and maternal health. These are the focused theme of the Government of India's public health programs under National Health Mission. It was Dakshata Program initiated in 2016 by Gol in 31 districts of the populous state of India, i.e., Uttar Pradesh. The investigation was carried out for these districts for the 124 high delivery load facilities selected from Health Management Information System data 2015-16. The random observations were undertaken for $2 \frac{1}{2}$ months (15 Sep - 30 Nov 2016). The quality of the services was assessed using indicators in form of human resource, infrastructure, availability of drugs and trays, staff practices and knowledge and documentation processes. It was observed that human resource was inadequate for the investigated facilities. Despite of designated delivery rooms in all districts, the infrastructural setup was in poor state. The availability of the drugs and trays was in worst state. The labor room staff hardly followed practices as per standard guidelines and lack the required knowledge. The documentation processes were inconsistent all over. Thus, the investigation concluded that governance need to strategize their approach of enhancing the intra partum services through Dakshata Program.
\end{abstract}

\section{Keywords: Goal: Child; Maternal}

\section{Introduction}

Goal 3 of Sustainable Development Goals (SDGs) which include the older version of Millenium Development Goals (MDGs) maternal health (MDG-5) and child health and survival (MDG-4) are prime focused themes under the National Health Mission (NHM) of Government of India (GoI) [1]. Reduction in the maternal mortality of the country to achieve SDG goal is far away. On the further analysis, there has been a significant change with steady decline found in Infant Mortality Rate (IMR) in last decade, while Early Neonatal Mortality Rate (ENMR) and Perinatal Mortality Rate (PNMR) remained steady since last decade [2].

Considering the fact that institutional deliveries raised significantly up to $73 \%$ across India after implementing Janani Suraksha Yojana (JSY) scheme, the major proportion of maternal mortality (44\%) and neonatal mortality (40\%) is still high on the period around child birth [2]. The majority of causes of maternal and newborn mortality are preventable through appropriate care to mother and newborn at the time of birth despite of having many strategies like Reproductive Maternal Neonatal Child and Adolescent Health (RMNCH+A). With the objective of improving the quality of care during child birth, GoI institutionalized 21 days training program of Skill Birth Attendance (SBA) for in-services Auxillary Nurse Midwives (ANMs) and staff nurses but results were not as according to expectations [2]. Subsequently, GoI introduced "Dakshata" which means adroitness, to improve intra partum and immediate post partum care with the training competency based and focusing on the highest impact practices during child birth, specifically shorter in duration for 3 days, post training follows up with support component by rolling out safe child birth checklist for doctors, staff nurses and ANMs. The Dakshata program was launched in 2016 in the highest populace state of Uttar Pradesh (UP), holding $16.16 \%$ (approx. $218.4 \mathrm{~m}$ ) population of India. The state government of UP decided to implement Dakshata program in 31 districts of the 75 districts of the state where no other program related to intrapartum care was implemented earlier [2].

The present investigation is an attempt to the assess the available infrastructure and services in the labor room, i.e., intra partum services along with infrastructural facilities. The investigation further documented current practices and knowledge of staff engaged for intrapartum care and early post partum services.

\section{Methodology}

\section{Study area and design}

The investigation was conducted for high delivery load facilities of 31 districts of Uttar Pradesh (India) (Table 1), where the State Government of UP decided to implement Dakshata program due to lack of any type of earlier interventions in these districts towards intra partum care. These 31 districts are non high priority districts, which consist approximately $36.6 \%$ of total population of Uttar Pradesh.

\section{Study period}

The investigation was undertaken for 124 facilities in 31 Dakshata districts from $15^{\text {th }}$ September to $30^{\text {th }}$ November 2016, on diurnal basis between 10:00 AM to 5:00 PM. Random approach was used by the observant, to collect the unbiased data of labor room commodities and the practices undertaken by labor room staff associated with intra partum care unit.

\section{Sample size}

On the basis of the year 2015-16 HMIS data, 4 high delivery load facilities were selected in each 31 districts, thus constituting the total 124 facilities across 31 Dakshata districts.

*Corresponding author: Mehra SP, Researcher, Environmental Professional cum Social Activist, Rajputana Society of Natural History, Rajputana's Shakuntalam, Village Ramnagar, PO Malah, Bharatpur 321001, Rajasthan, India, Tel: +91 9414165690; E-mail: drspmehra@yahoo.com

Received August 16, 2017; Accepted September 06, 2017; Published September 13, 2017

Citation: Parasher K, Kumar S, Gupta S, Rathore L, Mehra SP (2017) An Assessment of High Delivery Load Facilities under the Dakshata Program. Int J Waste Resour 7: 299. doi: 10.4172/2252-5211.1000299

Copyright: @ 2017 Parasher K, et al. This is an open-access article distributed under the terms of the Creative Commons Attribution License, which permits unrestricted use, distribution, and reproduction in any medium, provided the original author and source are credited. 


\begin{tabular}{|c|c|}
\hline Sr. No. & District Name (as per HMIS) \\
\hline 1. & Baghpat \\
\hline 2. & Bijnor \\
\hline 3. & Firozabad \\
\hline 4. & Gautam Buddha Nagar \\
\hline 5. & Ghaziabad \\
\hline 6. & Hapur \\
\hline 7. & Mainpuri \\
\hline 8. & Saharanpur \\
\hline 9. & Sambhal \\
\hline 10. & Shamli \\
\hline 11. & Ballia \\
\hline 12. & C S M Nagar \\
\hline 13. & Chandauli \\
\hline 14. & Deoria \\
\hline 15. & Fatehpur \\
\hline 16. & Ghazipur \\
\hline 17. & Kushinagar \\
\hline 18. & Mau \\
\hline 19. & Pratapgarh \\
\hline 20. & Sant Ravidas Nagar (Bhadohi) \\
\hline 21. & Auraiya \\
\hline 22. & Banda \\
\hline 23. & Chitrakoot \\
\hline 24. & Etawah \\
\hline 25. & Hamirpur \\
\hline 26. & Jalaun \\
\hline 27. & Jhansi \\
\hline 28. & Kanpur Dehat \\
\hline 29. & Lalitpur \\
\hline 30. & Lucknow \\
\hline 31. & Mahoba \\
\hline
\end{tabular}

Table 1: Investigated districts of uttar pradesh.

\section{Data collection and analysis (supplementary)}

The data from selected facilities were collected by 3 state technical specialists of UP- TSU (Technical Support Unit) and 19 Quality Improvement Mentors (QIM) of UP- NHM, who were trained on data collection tool, named LRGAT (Labor Room Gap Assessment Tool). LRGAT was prepared by State Dakshata Team at UP-TSU and pre-tested for one facility of randomly selected one district of each sub-region by 3 State Technical Specialists to ensure the quality and homogeneity of collected data. The training of filling LRGAT was also provided to 19 QIMs, the UP-NHM BSc nursing graduate staff with teaching experience. The Principal Investigators, 3 State Technical Specialists randomly cross verify collected data for precision of the data. The collected data were further analyzed for the results and outcomes.

\section{Observation and Results}

During the course of investigation of 124 facilities across 31 districts, total 30 District Hospitals, 51 CHC-FRU and 43 non-CHCFRU (Community Health Centre - First Referral Unit) were observed for the functional facilities for high delivery load on the basis of HMIS year 2015-16. The average delivery load on the facilities per month was $289 /$ month, which varies from 60 to 1240 per month in the range.

\section{Human resource}

As per the norms of MNH toolkit, published by Government of India, the total number of Gynaecologist, pediatrician and medical officer should be 400,124 and 480, while the government sanctioned posts were 213, 117 and 534 respectively across all the facilities. Subsequently, the available human resource were 152, 95 and 392 for Gynaecologist, pediatrician and medical officers respectively, which stated that there was not the only issue at planning level in minimum available positions required but also in the availability of human resources in every cadre. In the same vein the range 0 to 30,0 to 7 and 0 to 34 for Gynecologists, pediatrician and medical officers also indicated the underutilization of human resource at the district level.

\section{Infrastructure of delivery unit and labor room organization}

Labor room is an integral part of a delivery unit and it is mandatory to keep at least one labor room at each delivery point. Across all the 124 facilities designated delivery room was available only in $96 \%$ facilities. On the other hand, in terms of other facilities, separate waiting areas for attendants and ASHAs (Accredited Social Health Activists), dedicated receiving area for women in labor, post-delivery observation room for $2 \mathrm{hrs}$ and separate store rooms were only available in $62 \%, 56 \%, 49 \%$ and $43 \%$ facilities across the 31 districts respectively. Similarly, separate examination room for pre delivery examination for women in labor found only in $22 \%$ facilities and both pre delivery examination room and sterilization room was available only in $15 \%$ facilities that further raised the issue of available infrastructure to maintain the infection prevention practices around the labor room.

However, in the case of the organization of labor room, the condition was not much different. The availability of required labor table on the basis of delivery load, as per the MNH tool kit criteria, was found only $55 \%$ and that was a huge discrepancy that increases the unnecessary waiting period for delivery and pushes patients to face more labor pain. Apart from labor table, there were three other accessories, which makes it completely functional, these are Kelly's pad, mattress and Macintosh. Availability of the three accessories were $49 \%, 49 \%$ and $63 \%$ respectively, however, there were only $30 \%$ facilities where all the labor tables were equipped with all three accessories, that indicated that only $30 \%$ labor tables were functional completely.

The availability of attached toilet, 24 hrs water supply by tap and elbow tap in the labor room was $65 \%, 87 \%$ and $18 \%$ respectively, that indicated poor infrastructure for infection prevention strategy. On the other hand, the source of light in labor room was natural sun light normally but in the case of emergency, electricity with power back up either by generator or inverter was available in $94 \%$ labor rooms.

As per the MNH tool kit, newborn care corner is one an essential part of the labor room and the availability of newborn care corner was adequate and it was present in all labor rooms but the availability of essential accessories, which were indeed necessary for its functionality were the main concern. Only $91 \%$ radiant warmers were functional; mucus extractor, Ambu bag, shoulder roll were available in $81 \%, 29 \%$ and $79 \%$ facilities only. Subsequently, mask- 0 and 1 size were available only in approximately $50 \%$ facilities while both were present in only $18 \%$ facilities.

\section{Availability of drugs and trays}

To improve the functions and operation in the labor room, 7 trays concept has recently introduced through $\mathrm{MNH}$ guidelines, where are the essential commodities kept into the specific tray to use on time during delivery without delay. Surprisingly there was only $1 \%$ labor room, where all the seven trays were available. The availability of other trays were approximately $65 \%$ except for delivery tray which was present only in $6 \%$ labor rooms and labor tray is an essential tray, which uses in every delivery. 
Separate mercury based BP apparatus for labor room was only available in $67 \%$ facilities and rest of the facilities was using the $\mathrm{BP}$ apparatus available in the hospital on the basis of as or when required. However, availability of stethoscope was much better, which was $90 \%$ in labor rooms.

As per the norms, few essential drugs and commodities had to be available in the labor room, namely, oxytocin, magnesium sulfate, misoprostol, gentamycin, ampicillin, metronidazole, Vitamin $\mathrm{K}$, dexamethasone and IV fluid ringer lactate. None of the facility contained all the drugs at a time and the range was from $35 \%$ to $77 \%$ with variability. Oxytocin to protect post-partum hemorrhage after delivery in women and Vitamin $\mathrm{K}$ to prevent hemolytic disorders in newborns, which are essential drugs were present only in $50 \%$ and $35 \%$ facilities respectively. As per the Janani Suraksha Yojna (JSY), all the drugs must be provided by the facilities free of cost but at the ground level availability of drugs was the main challenge, which further increased the out of pocket expenditure of beneficiaries.

\section{Practices and knowledge of labor room staff}

The labor room staff needs to follow some practices in the labor room for quality intra partum care for well-being of mother and newborn. The use of Partograph to track the labor process is mandatory for all deliveries, which was followed by only $9 \%$ facilities. Further, knowledge of filling Partograph was also poor among the labor room staffs. Subsequently, knowledge about identification and management of maternal complications such as obstructed labor, preeclampsia was less constituting approximately $50 \%$. Bed head tickets had been used only in $52 \%$ facilities to record the status of mothers and newborns.

In the case of newborn management, only $32 \%$ staff could explain about essential new born care and 55\% knew about new born resuscitation with many discrepancies. $83 \%$ staff of facilities reported they promote early initiation of breast feeding and $78 \%$ facilities staff knew about 0 dose vaccination.

\section{Documentation process}

The labor room staff is expected to keep 12 records at the labor room as per the norms including Admission register, Bed head ticket, Delivery register, Referral slips, Referral registers, Maternal death register, PPIUCD register, PPIUCD follow up register, Maternal death register, MTP register, Drug stock register, Equipment stock register. The records were maintained by $27-97 \%$ labor rooms depending upon the type of registers. The quality of registers was poor, handmade far away from the standard prototype.

\section{Discussion}

The current cross sectional study at the beginning of the program was taken place to assess the available resources and adequacy of the available infrastructure, human resources, equipment, drugs, services to be provided in the labor room, largely looking at the basic commodities, infrastructure, and services related to intra partum care in the labor room that should be available. The study also documented the practices and knowledge of labor room staff and their documentation process under the normal government ambiance.

The availability of the Human Resource in terms of Gynecologists, Pediatricians, and Medical officers was the greatest concern at every level (including regular and contractual both). Stefan et al. also suggested that management of human resources is essential to any health care and how it can improve the output [3]. Many workers addressed the importance of human resource management in health care $[3,4]$. India is also facing the problem regarding lack of availability of trained and skilled health workers in terms of ANMs, SNs and doctors [4]. Redistribution of human resources in the facilities at the district level has a critical role thereafter [5]. Availability of human resources and its distribution in a country has great impact. Demand for health services in countries depends upon various characteristics such as economic factors, sociodemographic characteristics, etc. [5,6]. There are no clear guidelines from the government to decide from the state level regarding the rational distribution of human resources on the basis of the delivery load. Under the every newborn action plan, A study was conducted in 12 countries of Asia and Africa that also suggested that newborn resuscitation bottleneck is more severe than for essential newborn care [5]. The study also stated that neonatal resuscitation services are more critical at the district level. Subsequently, we found that only $33 \%$ facilities labor room staff knew about the essential new born care, but none of them could explain all the key steps of essential new born care. The same situation lies in the case of newborn resuscitation, where $55 \%$ labor room facilities staff knew about it while none of them could perform the steps of resuscitation in chronological order. Many models have been adopted worldwide to increase the efficiency of the health system for example outsourcing, contractual, etc. [5,6]. Filler et al. [7] also found that critical steps of resuscitation have not being followed and improved education and further training on resuscitation need to be imparted in labor room team [6]. Furthermore, availability of commodities in the newborn care corner for resuscitation is also an important bottleneck found in our surveys such as availability of functional radiant warmer and Ambu bag was approximately $80 \%$; shoulder roll $29 \%$; either availability of mask 0 or 1 was $50 \%$; availability of both masks was $28 \%$ [8].

The clean environment during birth reduces the risk of acquired newborn infection during the intra partum period $[9,10]$. The base line assessment shows mixed results in the case of infection prevention services. There is three kinds of practices found during infection prevention in the labor room, first is the personal maintenance of hygiene which includes wearing mask and caps or changing sleepers while entering in labor room is approximately $10 \%$. Second is practices during blood exposure which are wearing plastic apron during labor, wearing gloves during examination and wearing gloves for handling infectious waste are $66 \%, 87 \%$ and $75 \%$ respectively, Thirdly general infection prevention which includes the availability of 4 color coded bins and preparation of bleaching solution are $24 \%$ and $79 \%$. That denotes that health workers give maximum preference to follow practices of infection prevention while exposing to blood contamination related activities and next they focus on routine practices in the labor room and least they give preference to personal hygiene behavior. Rajesh et al. also coated in a study in the Gujarat state of India that 33\% facilities didn't have hand free water taps however in our study it was $18 \%$ and less than $5 \%$ facilities have protocol posters; he also stated that there is strong need to improve information system, protocols and with training and follow up mechanism [11]. UNICEF also identified the same situation in two states of Odisha and Rajasthan, India that general cleanliness and hygiene were absolutely absent, lack of awareness and poor supplies for the hand hygiene practice further increase the chances of exposure to health workers [12].

To determine the standardized infrastructure provision, the referral point is Indian Public Health Standards (IPHS) [13]. It was lacking in most of the cases for the facilities observed during the present investigation which was similar to the earlier one [14]. Similarly, the shortage of drugs in the labor room was quite common. The $10^{\text {th }} \mathrm{CRM}$ Report mentioned about the inadequate services and supply of drugs in 
many parts of nation in the past year 2016 [15]. Though the investigated facilities is small proportion of the country wide facilities but lacking of standards need attention.

The seminal work of Tanahashi [16] to develop coverage models for the evaluation of health services shows highlights the importance of availability of essential commodities such as drugs, vaccines and supplies and availability of human resources such as doctors, nurses, community health workers play key role in adequate functioning of the health system and specifically the delivery of evidence based interventions.

Yentis and Randall [17] conducted a survey of lead obstetric anesthetists in all consultant led maternity units in UK about drug errors and the measures taken to reduce or prevent them. Of the 179 out of $240(75 \%)$ who responded, 70 (39\%) knew of at least one drug error in their unit during the last year, with 28 of them (40\%) experiencing more than one. The recommended methods for reducing drug errors included use of colored labels, pre-filled labeled syringes, limiting the range of drugs available and keeping drugs in separate trays. Thus it is essential to arrange limited drugs and equipment in labeled and separate trays to ensure that essential medicine and equipment are available and the equipment and trays are arranged for a particular service.

However, in the present study only $1 \%$ facility had all the 7 recommended trays by GoI (Government of India). None of the facility contained all the drugs at the time of study, the range of availability of these supplies varied from $35 \%$ to $77 \%$. Essential medicines like oxytocin which can prevent post-partum hemorrhage, the leading cause of maternal death $-38 \%$ of all maternal deaths, was present only in $56 \%$ of facilities; similarly, the recommended antibiotics set of ampicillin, gentamicin and metronidazole were available in $38 \%$, $50 \%$ and $54 \%$ facilities implying that cases of maternal sepsis neither could be managed nor prevented adequately; magnesium sulphate was present in only $58 \%$ of facilities which is required to prevent maternal death from eclampsia and severe preeclampsia. Similarly, only $35 \%$ of facilities had Vitamin $\mathrm{K}$ that can reduce early neonatal mortality from hemorrhagic disorder; ambu bag was found only in $79 \%$ of facilities with $48 \%$ facilities having " 0 " size mask and 51\% facilities having " 1 " size mask which is required to reduce early neonatal mortality from leading cause of neonatal mortality - perinatal asphyxia or only $77 \%$ facilities had dexamethasone that can prevent death in preterm newborns. As per the Janani Shishu Suraksha Karyakram (JSSK), all the drugs must be provided by the facilities free of cost but at the ground level availability of drugs and simple equipment is a key challenge which is an obstacle to reduction in maternal and newborn deaths.

Regarding the services, the current base line survey found that only $9 \%$ facilities were using the partograph to assess the progress of labor, which is the most important practice for quality intra partum care and also to decide the referral and interventions for complicated deliveries. The present investigation found that negligible use of the Partograph to assess the progress of labor, which is the most important practice for quality intra partum care and also to decide the referral and interventions for complicated deliveries. However, Fawole et al. [18] found similar observations for African nationTheir work observed that only $9 \%$ facilities in southwest Nigeria have availability of Partographs and $16 \%$ staff has the knowledge about Partograph [18].

Documentation process is considered as one of the most important aspect for the preventive services [19]. Poor documentation is a major problem in the public health facilities specially in labor oom setting where quality of captured data is incomprehensive, lead to poor management and planning to improve the outcomes in terms of reducing maternal and neonatal deaths [20]. We found that availability of all records varies facility to facilities and maternal death registers found only at $29 \%$ facilities that could give a deeper insight for planning to prevent maternal death further. We also found that quality of captured data was very poor and all the mentioned section were not filled completely. Although guidelines for standard registers have already circulated through MNH toolkit but on most of the places, staff is using hand made, old registers which is incapable to collect data as required for planning to improve services in labor room. A study in Ghana also suggested that trainings to the health worker with follow up mechanism to ensure the quality of data can improve the further planning to achieve reduce the maternal mortality outcomes [21]. Kerber et al. [22] stated that health workers are the main source of collecting data at every steps in health care system to identify the best practices and flaws and that leads to create responsibility based health system not only at managers level but also at other level to reduce the systemic challenges.

\section{Conclusion}

The most important aspect is Human Resource Management in health sector of India followed by improvement in the quality of services. Health care quality refers to both the technical quality as well as sociocultural quality. Identification of the local barriers and incentives based on such researches could prove to be useful for strategize the policy. Ongoing monitoring and action to redress bottlenecks requires this stronger and more systematic assessment of district level causes. Also, there need to maintain health workforce statistics which enable to develop policies ensuring the equitable and effective distribution of the workforce. Existing thresholds for the required number of professional health workers provide valuable references for translating need into indicative workforce requirements. This should be considered part of the process of planning the workforce to meet the needs of the population. The strategy should promote effective coverage with health services staffed by a workforce that is both fit for purpose and fit to practice embedded in the post-2015 development agenda for health which require accountability and reporting mechanism.

\section{References}

1. Anon (2016) Accountability Initiative. Budget Briefs.

2. Anon (2015) Dakshata: Empowering providers for improved $\mathrm{MNH}$ care during institutional deliveries. A strategic initiative to strengthen quality of intra- and immediate postpartum care. Operational Guidelines. Maternal Health Division, Ministry of Health and Family Welfare, Government of India.

3. Stefane MK, Orchard C, Howard JM, Soriano MA, Leduc R (2006) The importance of human resources management in health care: A global context. Human Resources for Health 4: 1-20.

4. Rao KD, Bhatnagar A, Berman P (2012) So many, yet few: Human resources for health in India. Human Resources for Health 10: 19.

5. Enweronu-Laryea C, Dickson KE, Maxon SG, Simen-Kapeu A, Nyange C et al. (2015) Basic newborn care and neonatal resuscitation: A multi-country analysis of health system bottlenecks and potential solutions. BMC Pregnancy and Childbirth 15: S4.

6. WHO (2003) Shaping the future Geneva, World Health Report.

7. Finer N, Rich W (2010) Neonatal resuscitation for the preterm infant: evidence versus practice. J Perinatol 30: 57-66.

8. Kirti lyengar MJ (2014) Adherence to evidence based care practices for childbirth before and after a quality improvement intervention in health facilities of Rajasthan, India. BMC Pregnancy and Childbirth 14: 1471-2393.

9. USAID-MCHIP (2011) Better intrapartum practices to reduce newborn infections. 
Citation: Parasher K, Kumar S, Gupta S, Rathore L, Mehra SP (2017) An Assessment of High Delivery Load Facilities under the Dakshata Program. Int J Waste Resour 7: 299. doi: 10.4172/2252-5211.1000299

Page 5 of 5

10. Blencowe H, Cousens S, Mullany LC, Lee ACC, Kerber K, et al. (2011) Clean birth and postnatal care practices to reduce neonatal deaths from sepsis and tetanus: a systematic review and Delphi estimation of mortality effect. BMC Public Health 11: S11.

11. Mehta R, Mavalankar DV, Ramani KV, Sharma S, Hussein J (2011) Infection control in delivery care units, Gujarat state, India: A need assessment. BMC Pregnancy and Childbirth 11: 37.

12. Huskins W, Manchanda V, Singh N (2013) Infection control practices during labor and delivery and newborn care in resource limited settings: assessment and recommendations for improvement. Antimicrob Resist Infect Control 2: P269.

13. http://nhm.gov.in/nhm/nrhm/guidelines/indian-public-health-standards.html

14. Shah P (2016) MDGs to SDGs: Reproductive, maternal, newborn and child health in India. ORF Occasional Paper 103.

15. No Authors Listed (2016) Tenth common review mission report. 10th CRM report. Ministry of Health and Family Welfare,Government of India, Nirman Bhawan, New Delhi.

16. Tanahashi $T$ (1978) Health service coverage and its evaluation. Bull World Health Organ 56: 295-303.
17. Yentis SM, Randall K (2003) Drug errors in obstetric anaesthesia: a national survey. Int J Obstet Anesth 12: 246-249.

18. Fawole AO, Adekanle DA, Hunyinbo KI (2010) Utilization of the partograph in primary health care facilities in southwestern Nigeria. Niger J Clin Pract 13 200-204.

19. Gest KL, Margolis P, Bordley WC, Stuart J (2000) Measuring the process of preventive service delivery in primary care practices for children. Pediatrics 106: 879-885.

20. Mony PK, Jayanna K, Varghese B, Washington M, Vinotha P, et al. (2016) Adoption and completeness of documentation using a structured delivery record in secondary care, subdistrict Government Hospitals of Karnataka State India. Health Services Research and Managerial Epidemiology.

21. Danquah JB, Appah EK, Djan JO, Ofori M, Essegbey IT, et al. (1997) Improving recordkeeping for maternal mortality programs, Kumasi, Ghana. Int J Gynaecol Obstet 59: S149-55.

22. Kerber KJ, Mathai M, Lewis G (2015) Counting every stillbirth and neonatal death through mortality audit to improve quality of care for every pregnant woman and her baby. BMC Pregnancy and Childbirth 15: S9. 